\title{
Early Stillbirth
}

National Cancer Institute

\section{Source}

National Cancer Institute. Early Stillbirth. NCI Thesaurus. Code C120583.

Delivery of a dead fetus greater than 22 weeks but less than 28 weeks gestational age, and/or whose birth weight is greater than 500 grams but less than 1,000 grams. 